\title{
Design of Electrode Disk of Electrical Resistivity to Measure the Variations of Apparent Electrical Conductivity on Agricultural Land
}

\author{
Okto Ivansyah ${ }^{1}$, Tedy Setiawan ${ }^{2}$ \\ ${ }^{I}$ (Geophysics Engineering, polytechnic of pontianak, Indonesia) \\ ${ }_{2}^{2}$ (Geophysics Engineering, Institut Teknologi Bandung, Indonesia)
}

\begin{abstract}
A design of electrode disk device of Electrical Resistivity (ER) has been tested its stability of the data and its relationship closeness with the electrodes stick devices. The designed electrode device was easy to use and recorded data quickly and accurately. The design of this device consisted of a sleeve electrode, a diskshaped electrode, and shockbreaker; it was also equipped with wheels and a tool box. A testing process of the disk electrode device was done by measurements of apperant Electrical Conductivity (ECa) repeatedly to see the consistency of data measurement, with a correlation value of 0.988. The testing was also done by correlating the ECa data between the use of the disk electrode and the use of the stick electrode, with a correlation of 0.985 . The results of the testing showed that the disk electrode could be applied quickly and accurately to the ECa measurement of agricultural land with uneven topography and levees lied on rice fields.
\end{abstract}

Key words: Electrical Resistivity, apparent Electrical Conductivity, disk electrode device.

\section{Introduction}

Conventional agricultural treats the land in the same way such as the use of fertilizer, pesticide, tillage, and other inputs. Spatial heterogeneity of soil is one of several factors, which causes variations in the land that can affect crop yields. The inability of conventional agriculture to overcome the variations in land has not only an adverse economic impact due to reduced yields in certain regions, but also a negative impact on the environment due to the excessive use of agricultural chemicals, such as pesticide and fertilizer, which then become source of waste [1]. Measurement of soil physical properties is one of the solutions to overcome the drawbacks. The salinity level of the soil is the soil properties that greatly affect its ability to allow the crops to grow. Determination of the value of soil salinity can be done by measuring the electrical conductivity values of the soil [2]. Land power to conduct electricity (electric conductivity) is commonly used to assess soil dissolved salinity [3]. A high level of soil salinity will make the plants grow slowly, wilt or even die no matter how much water has been given [4].

Geophysical investigations in the field of agriculture focus on the zone of $1 \mathrm{~m}$ under the ground including the root of plants zone. Measurement of sub-surface shallow resistivity which has a good accuracy and is simple its data acquisition, attracts the attention of environmental geophysicists. It is a direct measurement of physical properties that is influenced not only the presence of a foreign body, but also the presence of chemicals from saturated liquid. This adaptation is then hampered by the use of Electrical Resistivity (ER) equipment which is developed to measure soil salinity [5] using the Wenner array. Electrical Resistivity is the most widely used in agriculture to measure the soil salinity by determinating the apparent Electrical Conductivity (ECa).

Development of ECa mobile tools combined with GPS has made the production of a map of the ECa on measurements at every few meters become possible. Veris Technologies Company [6] developed a commercial mobile system for ECa measurements using the principle of ER [7]. ER, which is connected to a GPS, (ie, Veris 3100) allows the continuous measurement of the ECa with time interval only a few seconds between readings, and produce readings at every few meters. A similar device, that is ARP 03, is used in agricultural land containing limestone mapping [8]. However, both types of ER mobile devices have never been tested on agricultural land that has uneven topography, especially rice fields that have dikes between them.

The topography of the agricultural land is one of the obstacles in data acquisition, so the ER should be made as flexible as possible. The ER mobile devices in the market today are able to produce a map of the ECa but they can not be applied to a land that has an uneven topography like rice field. In that case, the design of the ER electrode device that can be easily applied on agricultural land such as paddy field is obviously needed.

This paper will discuss the design of the electrode ER which is more flexible and mobile in its application on the rice farms, is capable of making measurements continuously, and has a range of measurement that can be set according to the need of the agricultural land such as paddy field. This electrode device is designed in disk-shaped to facilitate the movement of the device. 


\section{1}

\section{Disk Electrode of Electrical Resistivity}

\section{Electrode of Electrical Resistivity}

Electrode of the Electrical Resistivity is a device used to conduct electrical current into the soil or medium and to detect the potential difference of the electrical current injected. In the ER method, the current is injected into the earth using two current electrodes. Then, the potential difference generated will be measured using two potential electrodes. From the results of measurements of currents and potential for each different electrode spacing, it can be determined the variation of the resistivity of each layer below the point of measurement.

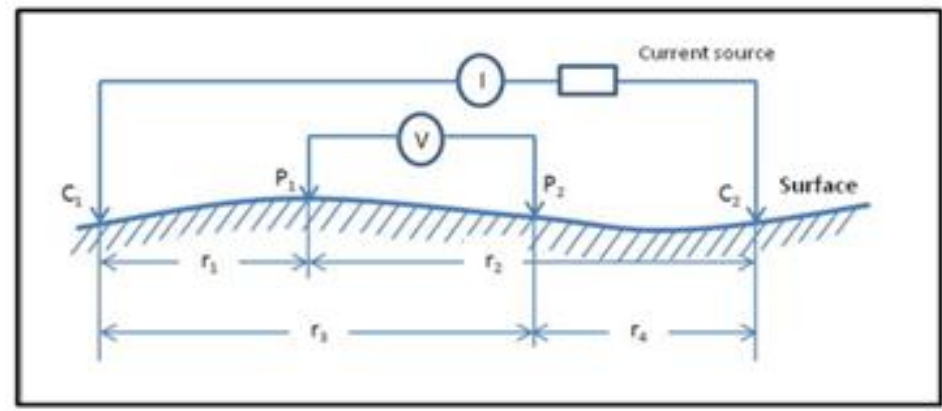

Fig.1. Scheme of two current electrodes and two potential electrodes on the surface of a homogeneous isotropic soil, adopted from [9].

The potential difference between points $\mathrm{P}_{1}$ and $\mathrm{P}_{2}$ can be obtained from equation (1),

$$
\Delta V=\frac{I \rho}{2 \pi}\left\{\left(\frac{1}{r_{2}}-\frac{1}{r_{2}}\right)-\left(\frac{1}{r_{3}}-\frac{1}{r_{4}}\right)\right\}
$$

where $r_{1}, r_{2}, r_{3}$ and $r_{4}$ is the electrodes spacing, as shown in Fig.1. This arrangement is associated with four electrodes that lie normally used in field.

\subsection{Electrode Design}

The ER electrodes device was designed to be able to work in mobile and to measure continuously and also to be applied on agricultural land such as paddy field of which topography was uneven and had dikes between fields. This device was made to facilitate geoelectric data collection process. The device consisted of four disk-shaped electrodes and was equipped with two wheels and a tool box for Resistivity Meter.

\section{Disk Electrode}

Electrical resistivity electrode device which was used in this research was in the form of disk consists of an electrode arm, a part of the disk-shaped electrode, and a part of spring (shockbreaker) electrode (Fig.2 a). An electrode arm served the connection of the disk to another part of the whole parts of these electrodes. The part of the disc-shaped electrode served as a conductor in direct contact with the ground and could rotate so that the device could measure continuously. On the other hand, the part of spring (shockbreaker) electrode allowed the arm electrode to move up and down when the disk electrode got a hitch bumps (or holes) so that the disk electrode kept touching the ground. The arm electrodes consist of the upper arm and forearm which were made from iron holo $(2 \times 4 \mathrm{~cm})$, while the disk eletrode was made of metal plate with a thickness of $3 \mathrm{~mm}$. The disk electrode has the following specifications:

- The length of the upper arm is $35 \mathrm{~cm}$

$0 \quad$ The length of the forearm is $40 \mathrm{~cm}$

- The diameter of disk electrode is $25 \mathrm{~cm}$

- The thickness of disk electrode is $3 \mathrm{~mm}$

$\circ \quad$ The length of the spring is $12 \mathrm{~cm}$

The distance between the electrode arms can also be set according to the desired depth of penetration of the users; with a maximum distance range of current electrode is $120 \mathrm{~cm}$ (and still can be improved further).

\section{Wheel}

The series wheel made the electrode device work more mobile. This circuit used wheels or tires which were made of rubber so they could be pumped with air. Wheel or tire rubber has a large coefficient of friction so that when rubbing the surface of the ground, it is expected to roll smoothly. The height of the electrode wheel 
circuit was designed so that it could be adjusted by the users, with the distance between wheels was fixed at 80 $\mathrm{cm}$ and the diameter of tire was $35 \mathrm{~cm} \varnothing$. The design of electrode wheels device can be seen in Fig. $2 \mathrm{~b}$.

\section{Tool box}

The tool box was used to store resistivity meter device and battery. It was made of a thin metal plate with the thickness of $1 \mathrm{~mm}$, and dry batteries. Its dimension had been adapted to Resistivity meter equipment with type of McOHM Mark Model-2115A-2. The tool box has the dimensions of $(31 \times 30 \times 13.5) \mathrm{cm}$, while of the battery box is $(9.5 \times 20 \times 11) \mathrm{cm}$. Tool box and battery box was covered with foam rubber which serves as a vibration dampening and shock absorbers (Fig. 2c).

\subsection{Testing}

\section{Measurements of Soil Apparent Electrical Conductivity (ECa)}

The testing of the disk electrode device was conducted by obtaining the soil electrical conductivity data. The value of the electrical conductivity of the soil is the inverse of soil resistivity, $\rho$, of which the values is calculated from the comparison of the current $(I)$ and voltage $(\Delta V)$ as in equation (2)

$\rho=2 \pi a \frac{\Delta V}{I}=2 \pi a R$

where $V$ is the voltage $(V), a$ is the distance between the electrodes $(m), I$ is the electric current $(A)$, and $R$ is the measured resistance $(\Omega)$.

The equation (2) can also be written as:

$$
E C a=\frac{1}{\rho}=\frac{1}{2 \pi a R}
$$
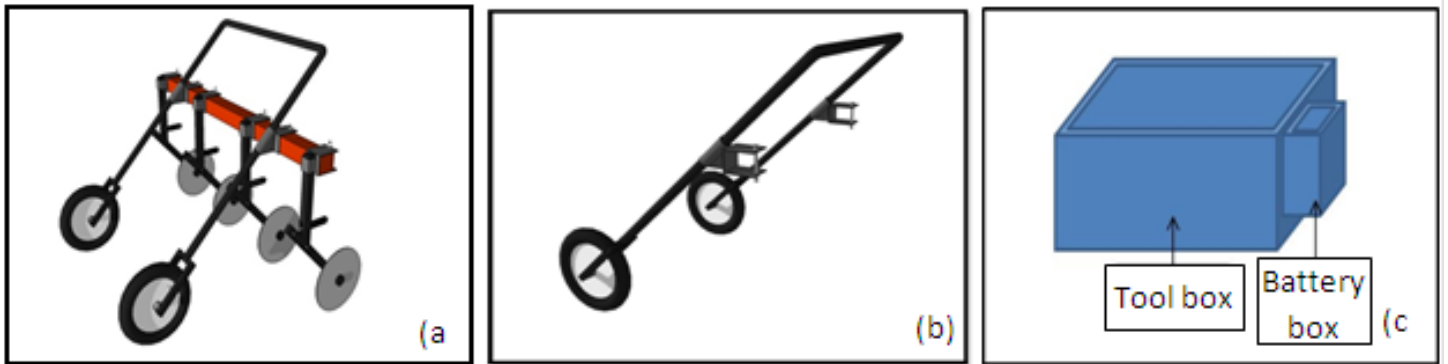

Fig.2. (a) Disk electrode design of electrical resistivity (b) Design wheel sets that will be applied to the disk electrode (c) The design of the tool box as a container resistivity meter and battery.

The data of ECa of soil at Basic Science B ITB yard was obtained by using a resistivity meter McOHM type-2115A Model Mark-2. The measurements were made on the track of $40 \mathrm{~m}$ long with the spacing between the measurement point was $2 \mathrm{~m}$.

The testing of the disk electrode device was conducted in two phases to ensure the data acquired is proper. The stages of the testing disk electrode device are as follows:

- The first phase, the correlation (r) soil apparent electrical conductivity (ECa) data on repeated measurements using disk electrode device was made. This stage was carried out in order to see the consistency of the data obtained using the disk electrode.

- The second phase, the correlation (r) soil apparent electrical conductivity (ECa) data on the measurement using the disk electrode device and the stick electrode was conducted. This stage was carried out in order to see the level of closeness of relations between the two data.

\subsection{Electrode Design}

\section{Result}

The electrode design which has been ready to use has the following specifications,

- Dimensions: 1 meter (length) x 1.2 m (width) x 1 meter (height)

- Weight : $12 \mathrm{Kg}$

- Wide stretch of electrodes: $10 \mathrm{~cm}$ (minimum) - $120 \mathrm{~cm}$ (maximum) 


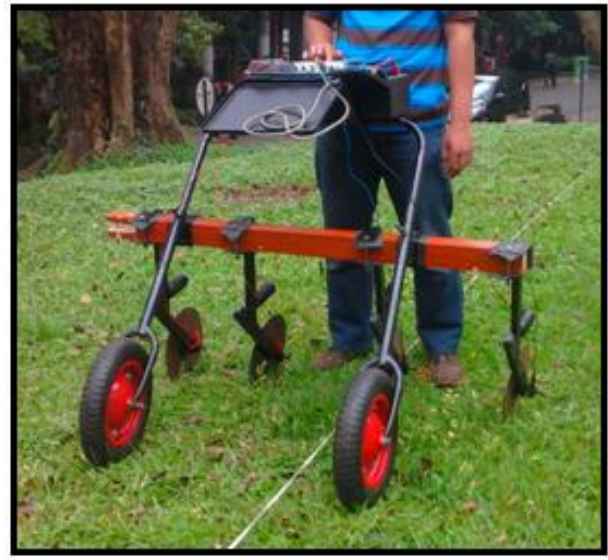

Fig.3. Disk electrode device of electrical resistivity

\subsection{Testing Disk Electrode}

The application of the electrical resistivity disk electrode designed (Fig. 4a) resulted the apparent electrical conductivity data that was satisfying and was in accordance with the desired design. The repeated measurements using disk electrode designs gave consistent data with a correlation value of 0.988 ; which showed a very good level of stability data (Fig. 5).
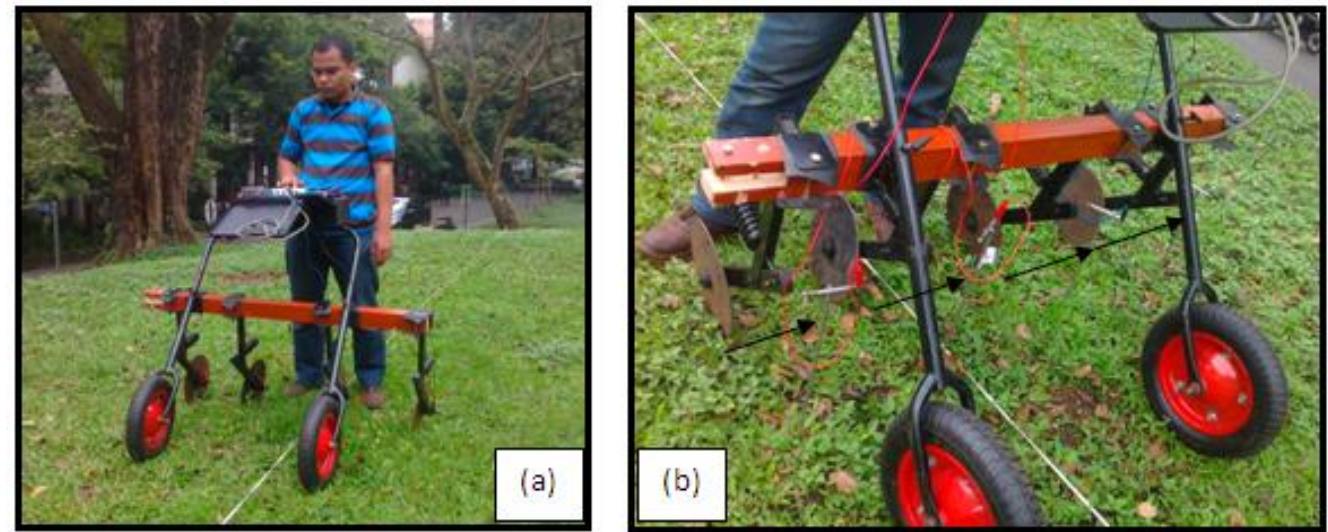

Fig.5. (a) The use of disk electrode device that has been designed. (b) The use of stick electrodes

On the other hand, the results of measurements using the disk electrode (Fig. 4a) and the stick electrode (Fig. 4b) showed a correlation value of 0.985; which explained that both data had a high degree of relationship (Fig. 6).

So, it can be said that the design of the disk electrode is able to be used as electrodes in the measurement of apparent electrical conductivity soil and can be applied on farms that have uneven topography and dykes on the rice field.

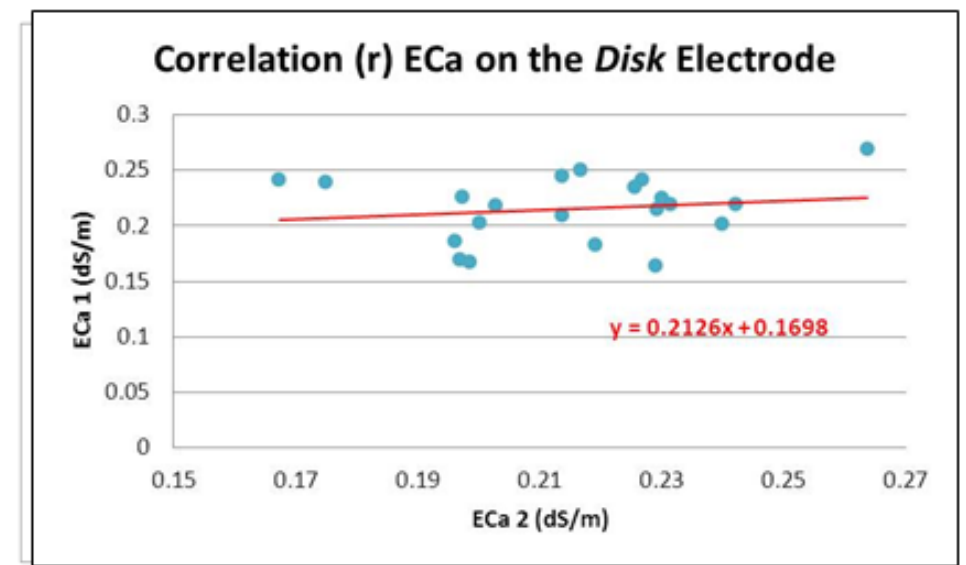

Fig.6. Graph of correlation (r) value of ECa on repeated measurements using the disk electrode. 


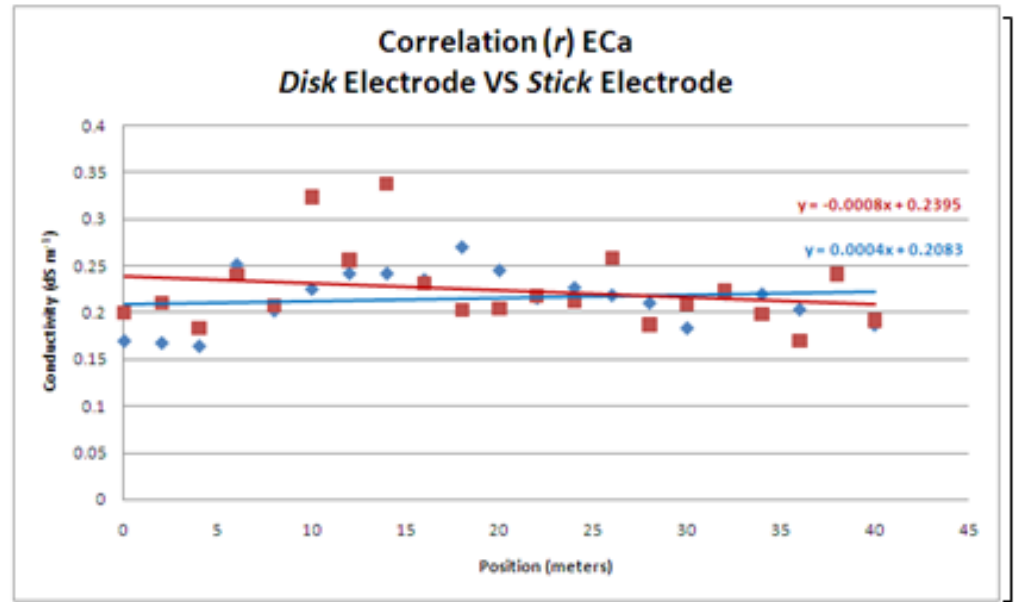

Fig.7. Graph of correlation (r) value of ECa on measurements using the disk electrode and sticks electrode

\section{Conclusion}

The design of the Electrical Resistivity disk electrode can be used as electrodes in the measurement of soil apparent electrical conductivity variation and can be implemented on farms that have uneven topography and dykes on the rice field. This is due to the data measurement results which tend to be stable and equal to another data measurement using stick electrode.

\section{References}

[1]. Dennis L. Corwin1 dan Scott M., Application of Geo-referenced Geophysical Measurements to Precision Agriculture. FastTimes, 2008, V.13 N.2: $29-37$.

[2]. Rhoades, J. D., F. Khanduvi, dan S. Lesch, Soil Salinity Assesment, FAO, Roma, 1999.

[3]. Notohadiprowiro, Tanah dan Lingkungan, Direktorat Jendral Pendidikan Tinggi Departemen Pendidikan dan Kebudayaan, Jakarta, (1998).

[4]. Tony Provin and J.L. Pitt., Managing Soil Salinity, Texas AgriLife Extension Service Publication, E-60, 3-12, 2001.

[5]. Rhoades, J.D. and R.D. Ingvalson., Determining salinity in field soils with soil resistance measurements Soil Sci. Soc. Am. Proc., 1971, 35: 54-60

[6]. Veris Teknologi., http://www.veristech.com/index.aspx ,1996.

[7]. Hamid F. Use of Geophysical Methods in Agriculture - Introduction, 2nd presentation, East NTSC, 2012.

[8]. [Priori S., M. Fantappiè., S. Magini, and E.A.C. Costantini., Using the ARP-03 for high-resolution mapping of calcic horizons, Int. Agrophys., 2013, 27, 313-321.

[9]. Reynolds, J. M., An Introduction to Applied and Environmental Geophysics, John Wiley \& Sons Ltd., UK, 1997. 